Article

\title{
Preparation and Evaluation of Core-Shell Magnetic Molecularly Imprinted Polymers for Solid-Phase Extraction and Determination of Sterigmatocystin in Food
}

\author{
Jing-Min Liu ${ }^{1,2}$, Shu-Yuan Wei ${ }^{3}$, Hui-Lin Liu ${ }^{1}$, Guo-Zhen Fang ${ }^{3}$ and Shuo Wang ${ }^{1,2, *}$ \\ 1 Beijing Advanced Innovation Center for Food Nutrition and Human Health, \\ Beijing Technology \& Business University (BTBU), Beijing 100048, China; \\ liujingmin@nankai.edu.cn (J.-M.L.); liuhuilin1290@163.com (H.-L.L.) \\ 2 Research Center of Food Science and Human Health, School of Medicine, Nankai University, \\ Tianjin 300071, China \\ 3 Key Laboratory of Food Nutrition and Safety, Ministry of Education, Tianjin University of Science and \\ Technology, Tianjin 300457, China; nkbluer@163.com (S.-Y.W.); fangguozhen@tust.edu.cn (G.-Z.F.) \\ * Correspondence: wangshuo@nankai.edu.cn; Tel.: +86-22-8535-8445
}

Received: 2 October 2017; Accepted: 17 October 2017; Published: 23 October 2017

\begin{abstract}
Magnetic molecularly imprinted polymers (MMIPs), combination of outstanding magnetism with specific selective binding capability for target molecules, have proven to be attractive in separation science and bio-applications. Herein, we proposed the core-shell magnetic molecularly imprinted polymers for food analysis, employing the $\mathrm{Fe}_{3} \mathrm{O}_{4}$ particles prepared by co-precipitation protocol as the magnetic core and MMIP film onto the silica layer as the recognition and adsorption of target analytes. The obtained MMIPs materials have been fully characterized by scanning electron microscope (SEM), Fourier transform infrared spectrometer (FT-IR), vibrating sample magnetometer (VSM), and re-binding experiments. Under the optimal conditions, the fabricated $\mathrm{Fe}_{3} \mathrm{O}_{4} @ \mathrm{MIPs}$ demonstrated fast adsorption equilibrium, a highly improved imprinting capacity, and excellent specificity to target sterigmatocystin (ST), which have been successfully applied as highly efficient solid-phase extraction materials followed by high-performance liquid chromatography (HPLC) analysis. The MMIP-based solid phase extraction (SPE) method gave linear response in the range of $0.05-5.0 \mathrm{mg} \cdot \mathrm{L}^{-1}$ with a detection limit of $9.1 \mu \mathrm{g} \cdot \mathrm{L}^{-1}$. Finally, the proposed method was used for the selective isolation and enrichment of ST in food samples with recoveries in the range $80.6-88.7 \%$ and the relative standard deviation (RSD) $<5.6 \%$.
\end{abstract}

Keywords: sterigmatocystin; molecularly imprinted polymers; magnetic nanoparticles; solid-phase extraction; HPLC

\section{Introduction}

Sterigmatocystin (ST), a carcinogenic mycotoxin, is a secondary metabolite produced mainly by Aspergillus versicolor, Aspergillus flavus, Aspergillus nidulans, fine wrinkles and other fungi Aspergillus [1-3]. With a basic structure composed of two furan rings with oxygen hetero anthraquinone, ST possess a similar structure to Aflatoxin B1 and its toxicity is second only to Aflatoxin that can induce liver cancer, lung cancer and other cancers [4,5]. Moreover, ST spreads widely in nature, and could contaminate most food and forage, especially wheat, corn, peanuts and forage, raising great concerns of public society [6,7]. For the quantification of ST in food samples, usually with complex matrix, liquid-liquid extraction or solid phase extraction coupled with high-performance 
liquid chromatography-mass spectrometry (HPLC-MS) has come to be an effective solution, of which the analytical performance highly depends on the adsorption materials [1].

Molecularly imprinted polymers (MIPs) have attracted much attention in the past decades for their high affinity and selectivity [8-10]. Molecular imprinting is a well-known method to create recognition sites structurally complementary to the target molecules in a synthetic polymer [11-13]. Generally, MIPs are fabricated via polymerization in the presence of template molecules followed by removal of the template. After the templates are wiped out, the remaining cavities are left behind which have complementary shape, size, and orientation of functionalities [14-16]. MIPs obtained with the memory of size, shape, and functional groups of the target molecules possess notable advantages, such as outstanding specificity, improved stability, cost-effective, ease of fabrication, and reversible adsorption/release, qualifying MIPs as ideal SPE materials $[17,18]$.

In recent years, with the involvement of nano/micro-structures as functional core, such as magnetic $\mathrm{Fe}_{3} \mathrm{O}_{4}$ nanoparticles [19], quantum dots [20,21], carbon nanomaterials [22], and upconversion nanoparticles [23,24], surface imprinting technique appeared as the advantageous protocol for fabrication of advanced MIPs materials with diverse functionalities. Therein, magnetic molecularly imprinted polymers (MMIPs), prepared via fabrication of the MIPs on the surface of a magnetic substrate, combined the outstanding magnetism with specific selective binding capability for target molecules, favoring rapid and easy removal of magnetic polymers from sample matrix by applying a magnetic field without the need for tedious filtration or centrifugation [25-28]. Compared with conventional MIPs, MMIPs demonstrate several superior features involving fast and effective binding to target analytes, magnetically susceptible characteristic, shorter pretreatment time, and reversible and controllable flocculation $[29,30]$. The magnetic separation process can be performed directly in crude samples containing suspended solid or other biological particles in a rapid and simple way, thus greatly saving time and cost. Therefore, a combination of magnetic separation and molecular imprinting would generate a powerful analytical method with simplicity, flexibility, and selectivity, especially as SPE adsorbents for complex sample analysis [28].

Herein, we proposed the core-shell MMIPs for food analysis, employing the $\mathrm{Fe}_{3} \mathrm{O}_{4}$ particles prepared by co-precipitation protocol as the magnetic core and MIP film onto the silica layer as the recognition and adsorption of target analytes. First, $\mathrm{Fe}_{3} \mathrm{O}_{4}$ particles were prepared by a solvothermal reduction method. Then, silica shell was deposited by adding tetraethyl ortosilicate (TEOS) and ammonia. Subsequently, the vinyl groups were grated onto silica-modified $\mathrm{Fe}_{3} \mathrm{O}_{4}$ surface by 3-methacryloyloxypropyltrimethoxysilane (MPS). The MIPs were coated on the $\mathrm{Fe}_{3} \mathrm{O}_{4} @ \mathrm{SiO}_{2}$ by the copolymerization of vinyl end groups with functional monomer, acrylamide, cross-linking agent, ethylene glycol dimethacrylate (EGDMA), the initiator, azobisisobutyronitrile (AIBN) and dummy template molecule, 1,8-dihydroxyanthraquinone (DT). The obtained MMIPs materials have been fully characterized by scanning electron microscope (SEM), Fourier transform infrared spectrometer (FT-IR), vibrating sample magnetometer (VSM), and re-binding experiments. Under the optimal conditions, the fabricated $\mathrm{Fe}_{3} \mathrm{O}_{4} @$ MIPs demonstrated fast adsorption equilibrium, a highly improved imprinting capacity, and excellent specificity to target ST, which have been successfully applied as highly efficient solid-phase extraction materials followed by HPLC analysis. The MMIP-based SPE method gave linear response in the range of $0.05-5.0 \mathrm{mg} \cdot \mathrm{L}^{-1}$ with a detection limit of $9.1 \mu \mathrm{g} \cdot \mathrm{L}^{-1}$.

\section{Materials and Methods}

\subsection{Chemicals and Materials}

All the reagents used were of analytical or HPLC grade. Tetraethyl ortosilicate (TEOS) was procured from Wuhan University Silicone New Material Co., Ltd. (Wuhan, China). Acrylamide (AM) was obtained from Tianjin Chemical Reagent Research Institute (Tianjin, China). Sterigmatocystin (99\%), DT, zearalenone (ZEN), aflatoxin B1 (AFB1), aflatoxin B2 (AFB2), aflatoxin M1 (AFM1), microcystin-leucine-arginine (MC-LR), ochratoxin A (OTA), vomitoxin (DON), and EGDMA (98\%) 
were obtained from Sigma-Aldrich (St. Louis, MO, USA). 2,2-azobisisobutyronitrile (AIBN; 99\%) was purchased from Tianjin Kermel Chemical Reagents Co. Ltd. (Tianjin, China). Acetonitrile, methanol, ethanol, $n$-hexane, acetone, and glacial acetic acid were obtained from Sinopharm Group Co. Ltd. (Tianjin, China). Iron (II) dichloride and iron (III) chloride were obtained from Chemicals Co. Ltd. (Tianjin, China). Highly purified water was obtained from a Pro Water System (Millipore Co. Ltd., Billerica, MA, USA). The food samples were randomly obtained from some local supermarkets (Tianjin, China). The samples of wheat and rice millet were purchased from a local supermarket (Tianjin, China). The ST-free samples were detected by HPLC. Caution is necessary when operating with toxins, wear the necessary personal protective equipment (PPE) including gloves and protective facial mask.

\subsection{Instrumentation}

Ultraviolet-visible (UV-vis) spectra over 200-800 nm was recorded on an Evolution 300 spectrophotometer (Thermo Fisher Scientific, Waltham, MA, USA). Scanning electron microscopy (SU 1510, Hitachi, Tokyo, Japan) was used to observe the shape, size and surface morphologies of $\mathrm{Fe}_{3} \mathrm{O}_{4}, \mathrm{Fe}_{3} \mathrm{O}_{4} @ \mathrm{SiO}_{2}, \mathrm{Fe}_{3} \mathrm{O}_{4} @ \mathrm{MIPs}$ and $\mathrm{Fe}_{3} \mathrm{O}_{4} @ \mathrm{NIPs}$ (non-imprinted polymers). Transmission electron microscope (TEM) images were obtained on a 2010 FEF microscope (JEOL, Tokyo, Japan). The infrared spectra were observed using a Tensor 27 FT-IR spectrophotometer (Bruker Company, Berlin, Germany). The magnetic intensity was evaluated using a 7410 VSM (Lake Shore Company, MA, USA). The analysis of HPLC was performed using HPLC (Shimadzu, Tokyo, Japan) with a variable wavelength UV-visible detector. A ZORBAX Eclipse XDB-C $\mathrm{C}_{18}(5 \mu \mathrm{m}, 250 \mathrm{~mm} \times 4.6 \mathrm{~mm}$, Shimadzu, Tokyo, Japan $)$ analytical column was used for the separation of analytes. The mobile phase was methanol/ $\mathrm{H}_{2} \mathrm{O}(4 / 1, v / v)$, and the flow rate was $0.7 \mathrm{~mL} \cdot \mathrm{min}^{-1}$ at $35^{\circ} \mathrm{C}$. The injection volume was $20 \mu \mathrm{L}$, and the wavelength of the UV detector was proceeding at $246 \mathrm{~nm}$.

\subsection{Synthesis of Silica Coated $\mathrm{Fe}_{3} \mathrm{O}_{4}$ Particles}

Referring to the reported solvothermal method [31], the $\mathrm{FeCl}_{3} \cdot 6 \mathrm{H}_{2} \mathrm{O}(1.35 \mathrm{~g}, 5 \mathrm{mmol})$ was dissolved in ethylene glycol (EG, $40 \mathrm{~mL}$ ), with continued stirring to form a clear solution, followed by the addition of NaAc ( $3.6 \mathrm{~g})$ and polyethylene glycol $(1.0 \mathrm{~g})$. The mixture solution was stirred vigorously for another $30 \mathrm{~min}$, and sealed in a teflon lined stainless-steel autoclave. The autoclave was heated to $200{ }^{\circ} \mathrm{C}$ and maintained for $8 \mathrm{~h}$, then cooled to room temperature after complete reaction. The black products were washed three times using ethanol with the assistance of external magnet isolation. The obtained magnetic $\mathrm{Fe}_{3} \mathrm{O}_{4}$ particles product was dried at $60^{\circ} \mathrm{C}$ for $6 \mathrm{~h}(0.26 \mathrm{~g}$ with a yield of $68.4 \%)$.

Thirty $\mathrm{mg}$ of $\mathrm{Fe}_{3} \mathrm{O}_{4}$ particles were dispersed in ethanol $(50 \mathrm{~mL})$, and $0.4 \mathrm{~mL}$ of TEOS was added, followed by cautious addition of $2 \mathrm{~mL}$ of ammonia water $(20 \%)$ dropwise. The reaction was allowed to proceed under continuous stirring for $8 \mathrm{~h}$ at room temperature, and the resultant product was repeatedly washed four times using ethanol by external magnets, dried in a vacuum oven at $60{ }^{\circ} \mathrm{C}$ for $10 \mathrm{~h}$ (38.4 mg with a yield of $86.7 \%$ ).

One hundred $\mathrm{mg}$ of thin silicon coated $\mathrm{Fe}_{3} \mathrm{O}_{4}$ particles were dispersed in isopropanol $(18 \mathrm{~mL})$, followed by addition of $0.5 \mathrm{~mL}$ of aqueous ammonia solution (30\%) under continued stirring. Then, excessive $\gamma$-methacryloxypropyl triethoxysilane ( $\gamma$-MAPs) was added drop by drop, and the mixture was allowed to react for $24 \mathrm{~h}$ at room temperature under continuous stirring. The resultant product was collected by an external magnetic field and rinsed with ethanol four times thoroughly, dried in the vacuum (98.2 $\mathrm{mg}$ with a yield of $98.2 \%)$.

\subsection{Preparation of Magnetic Core-Shell $\mathrm{Fe}_{3} \mathrm{O}_{4} @ M I P s$ and $\mathrm{Fe}_{3} \mathrm{O}_{4} @ N I P s$ Particles}

The MIPs were prepared by a precipitation polymerization approach. First, DT (120 mg) and acrylamide (AM) $(142.2 \mathrm{mg})$ was mixed with $30 \mathrm{~mL}$ of acetonitrile, with continuous stirring until completely dissolved, followed by addition of $100 \mathrm{mg}$ of $\mathrm{Fe}_{3} \mathrm{O}_{4} @ \mathrm{SiO}_{2}-\mathrm{MAPs}$. The mixed solution was kept under ultrasonic treatment (300 W, SB-5200D, SCIENTZ, Ningbo, China) for 15 min followed with 
forming template-monomer complex at $25^{\circ} \mathrm{C}$ for $3 \mathrm{~h}$. EGDMA (1.981 g) and AIBN $(60 \mathrm{mg})$ were added and then mixed the solution adequately with a $15-\mathrm{min}$ ultrasonic treatment. The mixed solution was transferred to a $250 \mathrm{~mL}$ three-necked flask followed by the addition of $70 \mathrm{~mL}$ of acetonitrile. Finally, nitrogen was purged in to remove oxygen and reaction proceeded by thermal polymerization at $60^{\circ} \mathrm{C}$ for $24 \mathrm{~h}$. The products were thoroughly grinded, filtrated through a 200-mesh sieve, and treated with $200 \mathrm{~mL}$ of acetone and acetonitrile $(9: 1, v / v)$ to remove the template. The washing efficiency was evaluated via UV-vis measurement $(429 \mathrm{~nm})$ of DT amount in supernatant solutions. Procedure of preparation of non-imprinted $\mathrm{Fe}_{3} \mathrm{O}_{4} @ \mathrm{NIPs}$ was the same to that of $\mathrm{Fe}_{3} \mathrm{O}_{4} @$ MIPs in the absence of the template DT. The obtained polymer products (MIP $\sim 680 \mathrm{mg}$, NIP $\sim 710 \mathrm{mg}$ ) was thoroughly washed by ethanol three times and dried under vacuum.

\subsection{Determination of Sterigmatocystin via Magnetic $\mathrm{Fe}_{3} \mathrm{O}_{4} @ M I P s$}

To investigate the recognition properties of $\mathrm{Fe}_{3} \mathrm{O}_{4} @$ MIPs and $\mathrm{Fe}_{3} \mathrm{O}_{4} @$ NIPs, the adsorption experiments were performed. Every test was performed thrice in parallel. Blank tests were performed by incubating MIP or NIP with water and measuring by HPLC to ensure there was no interferent existing in the polymers.

In the adsorption kinetics experiment, $5 \mathrm{mg}$ of $\mathrm{Fe}_{3} \mathrm{O}_{4} @ \mathrm{MIPs}$ or $\mathrm{Fe}_{3} \mathrm{O}_{4} @ \mathrm{NIPs}$ were added to $3 \mathrm{~mL}$ of ST solution $\left(20 \mathrm{mg} \cdot \mathrm{L}^{-1}\right)$, and incubated at regular time intervals from $10 \mathrm{~min}$ to $300 \mathrm{~min}$ at room temperature. After separating the supernatants and polymers using an external magnetic field, the concentration of ST in the supernatants was measured by a UV-visible spectrophotometer $(327 \mathrm{~nm})$. The amount of ST bound to the $\mathrm{Fe}_{3} \mathrm{O}_{4} @ \mathrm{MIPs}$ or $\mathrm{Fe}_{3} \mathrm{O}_{4} @$ NIPs was figured out by the formula.

In the isothermal binding experiment, $5 \mathrm{mg}$ of $\mathrm{Fe}_{3} \mathrm{O}_{4} @ \mathrm{MIPs}$ or $\mathrm{Fe}_{3} \mathrm{O}_{4} @ \mathrm{NIPs}$ were added to $3 \mathrm{~mL}$ methanol solution of ST of various concentrations from 2 to $50 \mathrm{mg} \cdot \mathrm{L}^{-1}$ and the mixture was incubated for $10 \mathrm{~min}$ at room temperature respectively. After incubation, the supernatants and polymers were separated by an external magnet, and the remaining ST in the supernatants was determined by UV-visible spectroscopy at $327 \mathrm{~nm}$.

In the selectivity experiments, AFB1 was selected as the structural analog. The $\mathrm{Fe}_{3} \mathrm{O}_{4} @ \mathrm{MIPs}$ or $\mathrm{Fe}_{3} \mathrm{O}_{4} @ \mathrm{NIPs}(25 \mathrm{mg})$ was placed in methanol solution of ST or AFB1 $\left(20 \mathrm{mg} \cdot \mathrm{L}^{-1}, 10 \mathrm{~mL}\right)$. After incubating for $4 \mathrm{~h}$ at room temperature, the supernatant and polymers were separated using an external magnetic field and the concentration of ST and its analog in the supernatant was determined by HPLC-UV. Moreover, to further verify the competitive recognition ability, $\mathrm{Fe}_{3} \mathrm{O}_{4} @ \mathrm{MIPs}(20 \mathrm{mg})$ was mixed with $10 \mathrm{~mL}$ methanol solution of ST and AFB1 $\left(20 \mathrm{mg} \cdot \mathrm{L}^{-1}\right.$ each). The extraction and determination procedures were then performed as described earlier for the static adsorption experiments. The same procedure was performed for the $\mathrm{Fe}_{3} \mathrm{O}_{4} @ \mathrm{NIPs}$.

\subsection{Adsorption Isotherms}

The Langmuir and Freundlich isotherm models were employed to evaluate the adsorption process. The widely used Langmuir equation, which was valid for monolayer sorption on a surface with a finite number of identical sites, is given by

$$
\frac{C_{e}}{q_{e}}=\frac{C_{e}}{Q_{m}}+\frac{1}{Q_{m} K_{l}}
$$

where $Q_{m}\left(\mathrm{mg} \cdot \mathrm{g}^{-1}\right)$ is the maximum adsorption capacity of adsorbent at monolayer, and $K_{l}$ is the Langmuir constants.

The essential characteristics of the Langmuir isotherm can also be expressed in terms of

$$
R_{l}=\frac{1}{1+K_{l} C_{0}}
$$


where $R_{l}$ is a dimensionless constant of separation factor or equilibrium parameter, which indicates the shape of adsorption isotherm.

The widely used empirical Freundlich equation, based on sorption on a heterogeneous surface, is given as:

$$
q_{e}=K_{F} C_{e}^{1 / n}
$$

where $K_{F}$ and $n$ are Freundlich constants indicating adsorption capacity and intensity, respectively, which can be calculated from linear plot of $\ln q_{e}$ against $\ln C_{e}$.

\subsection{Adsorption Kinetics Investigations}

To investigate the mechanism of sorption and potential rate controlling steps, the pseudo-firstorder, pseudo-second-order, intra-particle diffusion and Elovich model have been used to test the experimental data. The rate constants for four models have been determined and the correlation coefficients have been calculated in order to assess which model provides the best fit of the predicted data with the experimental results.

The pseudo-first-order kinetic model known as the Lagergern equation:

$$
\frac{d q}{d t}=K_{1}\left(q_{e}-q_{t}\right)
$$

where $q_{t}$ and $q_{e}$ are the amounts of ion adsorbed at time $t$ and at equilibrium $\left(\mathrm{mg} \cdot \mathrm{g}^{-1}\right)$, respectively, and $K_{1}$ is the rate constant of pseudo-first-order adsorption process $\left(\mathrm{min}^{-1}\right)$. After integration and applying boundary conditions, for $t=0, q=0$, the integrated form of equation becomes:

$$
\ln \left(q_{e}-q_{t}\right)=\ln q_{e}-K_{1} t
$$

The pseudo-second-order equation based on adsorption equilibrium capacity can be expressed as:

$$
\frac{d q}{d t}=K_{2}\left(q_{e}-q_{t}\right)^{2}
$$

where $K_{2}$ is the rate constant of pseudo-second-order sorption $\left(\mathrm{g} \cdot \mathrm{mg}^{-1} \cdot \mathrm{min}^{-1}\right)$. For $t=0, q=0$, it was given as:

$$
\frac{t}{q_{t}}=\frac{1}{K_{2} q_{e}^{2}}+\frac{t}{q_{e}}
$$

The Elovich equation was also be applied to analyze the adsorption data. Its linear form was given as:

$$
q_{t}=\frac{1}{\beta} \ln (\alpha \beta)+\frac{1}{\beta} \ln (t)
$$

where $\alpha$ is the initial sorption rate constant $\left(\mathrm{mg} \cdot \mathrm{g}^{-1} \cdot \mathrm{min}^{-1}\right)$, and the parameter $\beta$ is related to the extent of surface coverage and activation energy for chemisorption $\left(\mathrm{g} \cdot \mathrm{mg}^{-1}\right) . \alpha, \beta$ can be obtained from the slope and intercept of the plot of $q_{t}$ versus $\ln t$.

The intra-particle diffusion model was also tested. The initial rate of intra-particle diffusion is as follows:

$$
q_{t}=k_{i n t} t^{1 / 2}+C
$$

where $k_{\text {int }}$ is the intra-particle diffusion rate constant $\left(\mathrm{mg} \cdot \mathrm{g}^{-1} \cdot \mathrm{min}^{-1 / 2}\right)$, and $C$ is the intercept.

\subsection{Real Sample Analysis}

All food samples were free of ST, and the spiking concentrations were $50 \mu \mathrm{g} \cdot \mathrm{kg}^{-1}, 100 \mu \mathrm{g} \cdot \mathrm{kg}^{-1}$, and $200 \mu \mathrm{g} \cdot \mathrm{kg}^{-1}$. The food sample $(1.0 \mathrm{~g})$ was accurately weighed in a $25-\mathrm{mL}$ conical flask with a stopper, and then different amounts of ST standard solutions were added $\left(5 \mathrm{mg} \cdot \mathrm{L}^{-1}, 50 \mu \mathrm{L}, 100 \mu \mathrm{L}\right.$, 
and $200 \mu \mathrm{L}$, dissolved in methanol). After thoroughly incorporated, the mixture stands overnight. Ten milliliters of $n$-hexane were added, and the mixture was treated by ultrasonic for $10 \mathrm{~min}$. Exactly $3.0 \mathrm{~mL}$ of the supernatant solution was added to another $25-\mathrm{mL}$ conical flask. Typically, $15.0 \mathrm{mg}$ of $\mathrm{Fe}_{3} \mathrm{O}_{4} @$ MIPs were added and shaken at $120 \mathrm{rpm}$ for $50 \mathrm{~min}$ at room temperature on a shaker (MS 3 digital, IKA, Berlin, Germany). The supernatant and polymers were separated using an external magnetic field. After removing the supernatant solution, the $\mathrm{Fe}_{3} \mathrm{O}_{4} @ \mathrm{MIPs}$ was washed with $1 \mathrm{~mL}$ of $n$-hexane/ether $(4: 1, v / v)$ to eliminate the co-extracted impurities. Then, the ST was eluted from the $\mathrm{Fe}_{3} \mathrm{O}_{4} @ \mathrm{MIPs}$ with $3 \times 1.0 \mathrm{~mL}$ of chloroform, and the elutes were combined together and evaporated to almost dryness under a stream of nitrogen. The residue was re-dissolved by $1.0 \mathrm{~mL}$ of chromatographic pure methanol, and filtered through a $0.45 \mu \mathrm{m}$ organic membrane, and finally detected by HPLC.

\section{Results and Discussion}

\subsection{Preparation and Characterization of Imprinted Magnetic Nanoparticles}

When constructing the MIP materials, a dummy template molecule is often employed as an alternative template for imprinting instead of the target analyte, in the case that the target analyte is highly toxic, expensive or unavailable [15,32]. The dummy template should possess the similar structure and physicochemical property to the target molecules and scarcely present in the related sample matrix to avoid possible interference. In the previously-reported work, DT was a widely-used dummy template molecule for imprinting of ST, due to the high price and toxicity of ST [22,24]. Therefore, the magnetic molecularly imprinted polymers for recognizing ST specifically were synthesized using DT as the dummy template molecule, which has similar structure with ST and hardly presents in the grain samples. The preparation procedure of $\mathrm{Fe}_{3} \mathrm{O}_{4} @ \mathrm{MIPs}$ by the precipitation polymerization is shown in Figure 1. Super paramagnetic $\mathrm{Fe}_{3} \mathrm{O}_{4}$ nanoparticles were synthesized by the solvothermal method to provide a good magnetic core, supporting the MIPs material magnetic response. The surface of the $\mathrm{Fe}_{3} \mathrm{O}_{4}$ core was encapsulated with $\mathrm{SiO}_{2}$ shell by TEOS to avoid the oxidation and provide silanol groups at the surface, which make them biocompatible and easily modified with various functional groups. Furthermore, silica shell could not only shield the magnetic dipolar attraction between magnetic particles, in favor of the dispersion of magnetic particles in solvent, but also protect $\mathrm{Fe}_{3} \mathrm{O}_{4}$ from dissolving in an acidic environment.

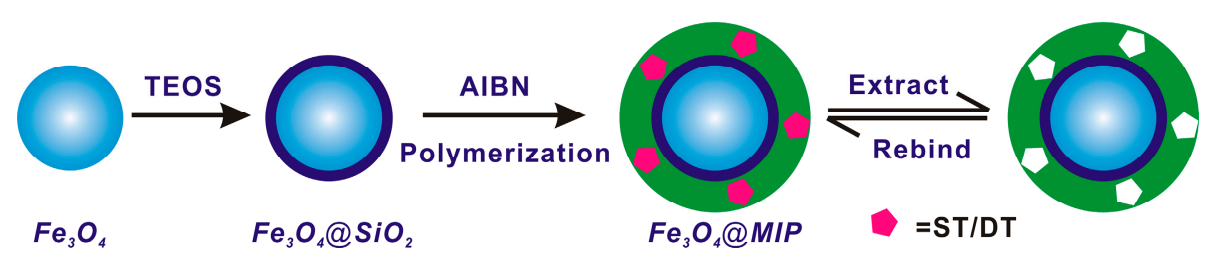

Figure 1. Schematic illustration of $\mathrm{Fe}_{3} \mathrm{O}_{4}$-involved magnetic molecularly imprinted polymers for sensitive and specific recognition of sterigmatocystin. TEOS: tetraethyl ortosilicate; AIBN: 2,2-azobisisobutyronitrile; MIP: molecularly imprinted polymers; ST: sterigmatocystin; DT: 1,8-dihydroxyanthraquinone.

To introduce vinyl groups, the hydroxyl groups on surface of $\mathrm{Fe}_{3} \mathrm{O}_{4} @ \mathrm{SiO}_{2}$ were further reacted with MPS, which subsequently reacted in the synthesis of MIPs or NIPs. In addition, the $\mathrm{Fe}_{3} \mathrm{O}_{4} @ \mathrm{SiO}_{2}$ particles had a small diameter with an extremely high surface area-to-volume ratio, so that the MIPs formed easily at the surface of the magnetic particles. The MIPs shells were coated on the surface of $\mathrm{Fe}_{3} \mathrm{O}_{4} @ \mathrm{SiO}_{2}$ by the copolymerization of functional monomer (AM), cross-linking agent (EGDMA), initiator (AIBN) and template molecule (DT). After removal of the templates, the $\mathrm{Fe}_{3} \mathrm{O}_{4} @ \mathrm{MIPs}$ particles were obtained. Overall, the $\mathrm{Fe}_{3} \mathrm{O}_{4} @ \mathrm{MIPs}$ particles could recognize and adsorb the targets effectively and were also easily collected using an external magnetic field. Meanwhile, $\mathrm{Fe}_{3} \mathrm{O}_{4} @ \mathrm{NIPs}$ were also prepared with the same procedure, but without the addition of template DT. 
The FT-IR spectroscopy of $\mathrm{Fe}_{3} \mathrm{O}_{4}, \mathrm{Fe}_{3} \mathrm{O}_{4} @ \mathrm{SiO}_{2}, \mathrm{Fe}_{3} \mathrm{O}_{4} @$ MIPs and $\mathrm{Fe}_{3} \mathrm{O}_{4} @$ NIPs is shown in Figure 2A. The $\mathrm{Fe}-\mathrm{O}$ stretching vibration can be observed at $588 \cdot \mathrm{cm}^{-1}$. Compared with the absorption bands of pure $\mathrm{Fe}_{3} \mathrm{O}_{4}$, the characteristic absorption peaks of $\mathrm{Si}-\mathrm{O}-\mathrm{Si}$ at $1151 \cdot \mathrm{cm}^{-1}$ and $\mathrm{O}-\mathrm{H}$ group at $1641 \cdot \mathrm{cm}^{-1}$ confirmed the formation of silica on the surface of $\mathrm{Fe}_{3} \mathrm{O}_{4}$ after the modification with TEOS and MAPs. Peaks of $\mathrm{C}=\mathrm{O}$ stretching vibration at $1641 \mathrm{~cm}^{-1}$ and $\mathrm{C}-\mathrm{H}$ stretching vibration of the methyl group at $3072 \mathrm{~cm}^{-1}$ indicated that the AM-EGDMA layer was successfully formed on the surface of $\mathrm{Fe}_{3} \mathrm{O}_{4} @ \mathrm{SiO}_{2}$. In addition, $\mathrm{Fe}_{3} \mathrm{O}_{4} @ \mathrm{MIPs}$ and $\mathrm{Fe}_{3} \mathrm{O}_{4} @ \mathrm{NIPs}$ showed almost the same characteristic absorption bands, revealing the complete removal of templates. These results proved the successful preparation of MIPs and NIPs on the surface of $\mathrm{Fe}_{3} \mathrm{O}_{4} @ \mathrm{SiO}_{2}$.
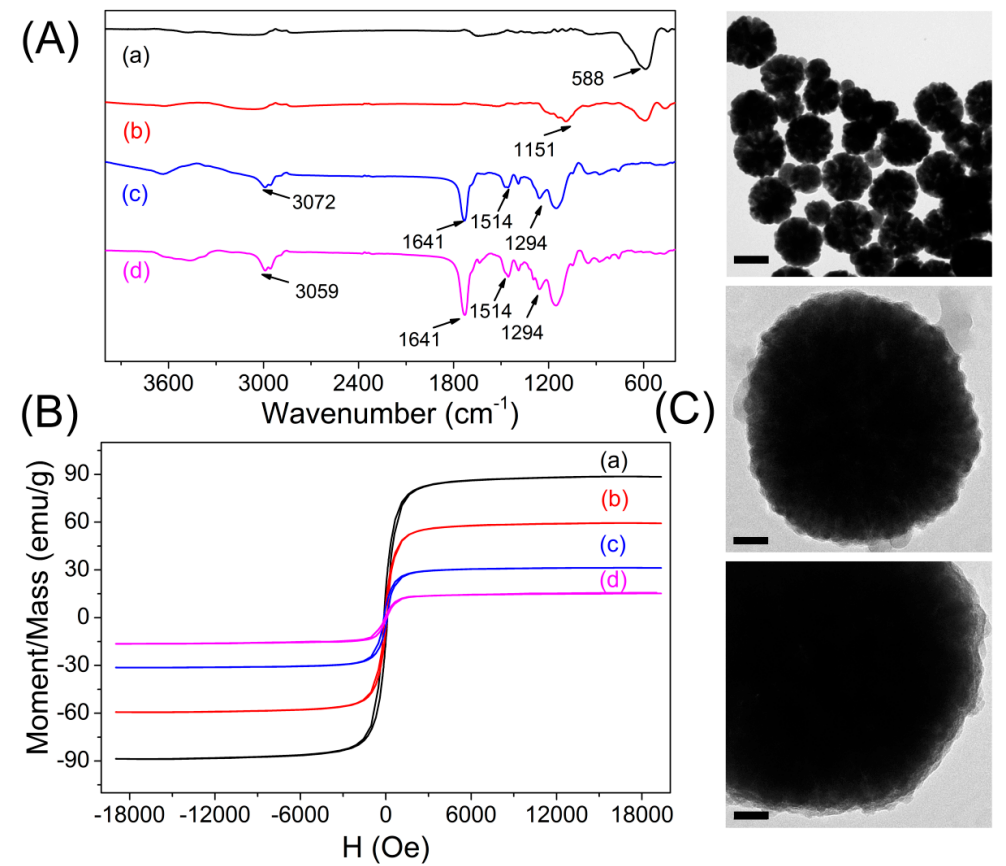

Figure 2. (A) Fourier transform infrared spectrometer analysis of: $\mathrm{Fe}_{3} \mathrm{O}_{4}$ (a); $\mathrm{Fe}_{3} \mathrm{O}_{4} @ \mathrm{SiO}_{2}$ (b); $\mathrm{Fe}_{3} \mathrm{O}_{4} @$ MIPs (molecularly imprinted polymers) (c); and $\mathrm{Fe}_{3} \mathrm{O}_{4} @ \mathrm{NIPs}$ (non-imprinted polymers) (d). (B) Magnetization curves of: $\mathrm{Fe}_{3} \mathrm{O}_{4}(\mathrm{a}) ; \mathrm{Fe}_{3} \mathrm{O}_{4} @ \mathrm{SiO}_{2}$ (b); vinyl-modified $\mathrm{Fe}_{3} \mathrm{O}_{4}$ (c); and $\mathrm{Fe}_{3} \mathrm{O}_{4} @ \mathrm{MIPs}$ (d). (C) Typical high-resolution transmission electron microscopy (HRTEM) photographs of the $\mathrm{Fe}_{3} \mathrm{O}_{4}$ (top, scale bars $=300 \mathrm{~nm}$ ), and $\mathrm{Fe}_{3} \mathrm{O}_{4} @ \mathrm{SiO}_{2}$ (middle and bottom, scale bars $=50 \mathrm{~nm}$ ). H: magnetic field.

Magnetic property is crucial to the magnetic particles for their application in fast separation. VSM was employed to study the magnetic properties of the synthesized magnetic particles, and the magnetic hysteresis loop of the dried samples at room temperature is illustrated in Figure 2B. It is obvious that there is no hysteresis, both remanence and coercivity are zero, suggesting that the samples are superparamagnetism. The saturation magnetization values obtained at room temperature were $88.73 \mathrm{emu} \cdot \mathrm{g}^{-1}, 59.45 \mathrm{emu} \cdot \mathrm{g}^{-1}, 31.36 \mathrm{emu} \cdot \mathrm{g}^{-1}$, and $15.17 \mathrm{emu} \cdot \mathrm{g}^{-1}$ for $\mathrm{Fe}_{3} \mathrm{O}_{4}, \mathrm{Fe}_{3} \mathrm{O}_{4} @ \mathrm{SiO}_{2}$, vinyl-modified $\mathrm{Fe}_{3} \mathrm{O}_{4} @ \mathrm{SiO}_{2}$ and $\mathrm{Fe}_{3} \mathrm{O}_{4} @ \mathrm{MIPs}$, respectively. The theoretical value of saturation magnetization for bulk magnetite is reported to be $92 \mathrm{emu} \cdot \mathrm{g}^{-1}$. The decrease in magnetization value can be attributed to the small particle surface effect such as magnetically inactive layer containing spins that are not collinear with the magnetic field. The saturation magnetization of $\mathrm{Fe}_{3} \mathrm{O}_{4} @ \mathrm{MIPs}$ was reduced to $15.17 \mathrm{emu} \cdot \mathrm{g}^{-1}$ in comparison with the pure $\mathrm{Fe}_{3} \mathrm{O}_{4}$, but remained strongly magnetic at room temperature and qualified as effective magnetic separation carriers.

TEM, SEM, and dynamic light scattering (DLS) characterizations revealed that the as-synthesized $\mathrm{Fe}_{3} \mathrm{O}_{4}$ particles possessed an average diameter of $\sim 370 \mathrm{~nm}$. After the modification with TEOS, a thin silicon layer coated on the surface of $\mathrm{Fe}_{3} \mathrm{O}_{4}$ could be distinguished, with the size increased to $\sim 480 \mathrm{~nm}$, 
which also confirmed the successful preparation of the core-shell structure $\mathrm{Fe}_{3} \mathrm{O}_{4} @ \mathrm{SiO}_{2}$. In comparison, the $\mathrm{Fe}_{3} \mathrm{O}_{4} @ \mathrm{MIPs}$, with an average diameter of $\sim 830 \mathrm{~nm}$, structures seemed more rough and dense than the $\mathrm{Fe}_{3} \mathrm{O}_{4} @ \mathrm{NIPs}$ (average diameter of $\sim 1.23 \mu \mathrm{m}$ ), indicating the template molecule showed obvious influence over the surface topography. Consequently, this uniform structure of MIP materials would facilitate the mass transport between solution and the shell surface of $\mathrm{Fe}_{3} \mathrm{O}_{4} @ \mathrm{MIPs}$ as SPE adsorbents (Figures 2C and 3).

Experimental conditions, including MMIPs amount and organic media used for SPE assay, have been fully optimized. Results in Figure 4 indicated the MMIPs amount showed insignificant influence over the recovery, thus chose the relative small amount of $5 \mathrm{mg}$ for all assays. When using $n$-hexane as the sampling media and chloroform as the eluting media, best SPE performance was achieved. It was also found that $\mathrm{pH}$ showed little influence on the adsorption, probably because there was limited electrostatic interaction in the adsorption process that carried out all in non-aqueous solvents.
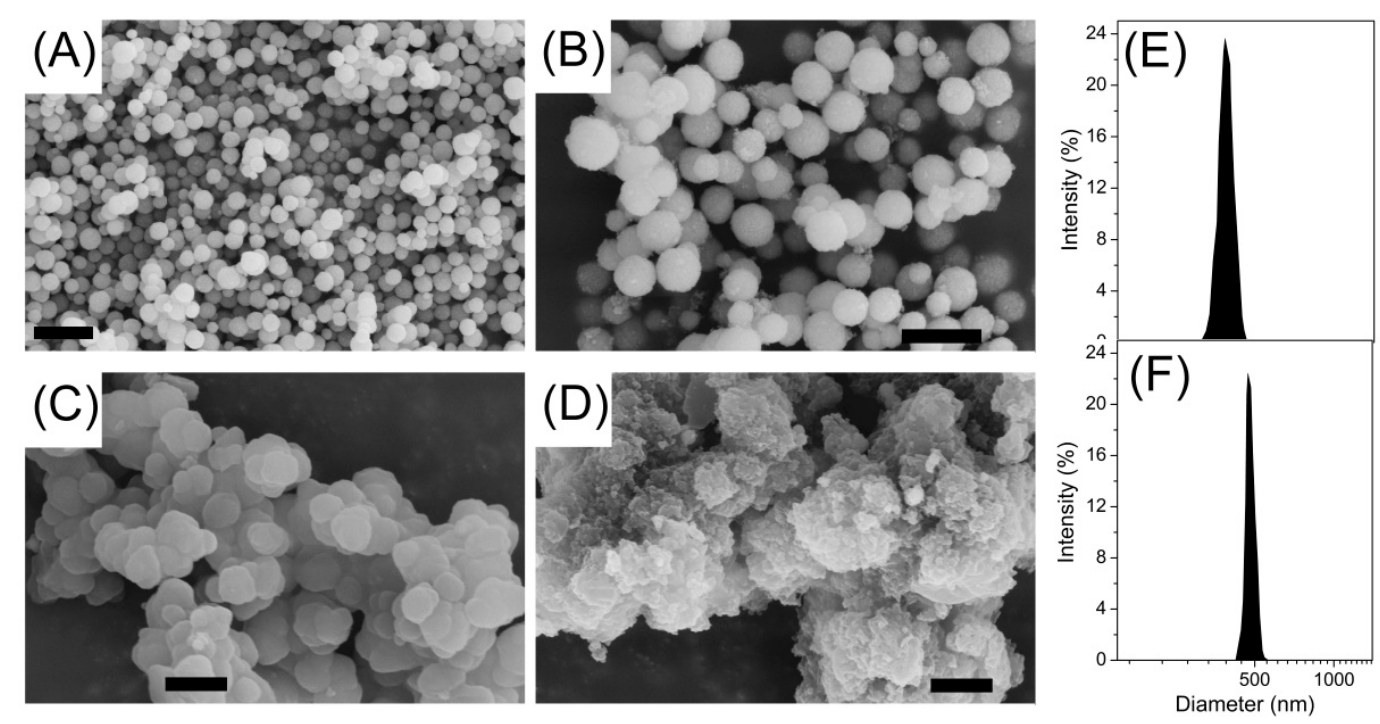

Figure 3. The typical scanning electron microscopy (SEM) photographs of the as-prepared particles: $\mathrm{Fe}_{3} \mathrm{O}_{4}(\mathbf{A}) ; \mathrm{Fe}_{3} \mathrm{O}_{4} @ S \mathrm{SiO}_{2}(\mathbf{B}) ; \mathrm{Fe}_{3} \mathrm{O}_{4} @ \mathrm{MIPs}(\mathbf{C})$ and $\mathrm{Fe}_{3} \mathrm{O}_{4} @ \mathrm{NIPs}(\mathbf{D})$; size distribution of the $\mathrm{Fe}_{3} \mathrm{O}_{4}(\mathbf{E})$; and $\mathrm{Fe}_{3} \mathrm{O}_{4} @ \mathrm{SiO}_{2}(\mathbf{F})$. The scale bars all represent $1 \mu \mathrm{m}$.

\subsection{MIPs Recognition of Sterigmatocystin}

The binding isotherms of ST onto $\mathrm{Fe}_{3} \mathrm{O}_{4} @$ MIPs and $\mathrm{Fe}_{3} \mathrm{O}_{4} @ \mathrm{NIPs}$ were determined in the concentration range of $0-50 \mathrm{mg} \cdot \mathrm{L}^{-1}$, and the results are shown in Figure 4A. Molecular recognition of $\mathrm{Fe}_{3} \mathrm{O}_{4} @ \mathrm{MIPs}$ and $\mathrm{Fe}_{3} \mathrm{O}_{4} @$ NIPs particles increased rapidly with increasing initial concentration, and became relatively flat and reached its saturation at high ST concentration. The amount of ST bound to the $\mathrm{Fe}_{3} \mathrm{O}_{4} @$ MIPs was significantly higher than that of the $\mathrm{Fe}_{3} \mathrm{O}_{4} @ \mathrm{NIPs}$ at the same initial concentration. The recognition ability of $\mathrm{Fe}_{3} \mathrm{O}_{4} @$ MIPs particles towards ST was investigated by adsorption kinetics. The adsorption kinetics of $20 \mathrm{mg} \cdot \mathrm{L}^{-1}$ ST solution to $\mathrm{Fe}_{3} \mathrm{O}_{4} @ \mathrm{MIPs}$ and $\mathrm{Fe}_{3} \mathrm{O}_{4} @ \mathrm{NIPs}$ are shown in Figure 4B. The adsorption capacity increased with time, and the $\mathrm{Fe}_{3} \mathrm{O}_{4} @ \mathrm{MIPs}$ showed a fast adsorption rate. The adsorption capacity increased rapidly in the first $30 \mathrm{~min}$ and almost reached equilibrium after $2 \mathrm{~h}$. Most of the recognition sites of the imprinted polymers are on the surface of the imprinted magnetic particles, facilitating high adsorption efficiency.

The adsorption process was interpreted both with Langmuir and Freundlich isotherm models. Comparison of the calculated data from Langmuir and Freundlich isotherm models indicated the obtained data is better fitted with Langmuir model than with Freundlich model, revealing the adsorption was more similar to a monolayer adsorption process rather than a multiple process. The Langmuir constant $R_{l}$ was in the range of $0-1$, which indicated favorable adsorption of MMIP 
to the analytes (Table 1). The models of the pseudo-first-order, pseudo-second-order, intra-particle diffusion and Elovich model were employed to evaluate the kinetic mechanism. It was noticed that pseudo-second-order equation provided the better $R^{2}$ and agreement between calculated $q_{e}$ values and the experimental $q_{e}(\exp )$ value (0.95), whereas the pseudo-first-order, Elvoich and intra-particle diffusion equations did not give a good fit to the experimental data for the adsorption of ST (Table 1).

The regeneration ability and the stability of $\mathrm{Fe}_{3} \mathrm{O}_{4} @ \mathrm{MIPs}$ materials were evaluated by spacing and non-spacing adsorption and elution cycles, and the SPE efficiency was assessed by observing the changes of the recovery. The results indicated that the MIPs were stable in the cycle tests, specifically in more than 20 adsorption-elution cycles with stable SPE recoveries of the target analyte (Figure 4C).
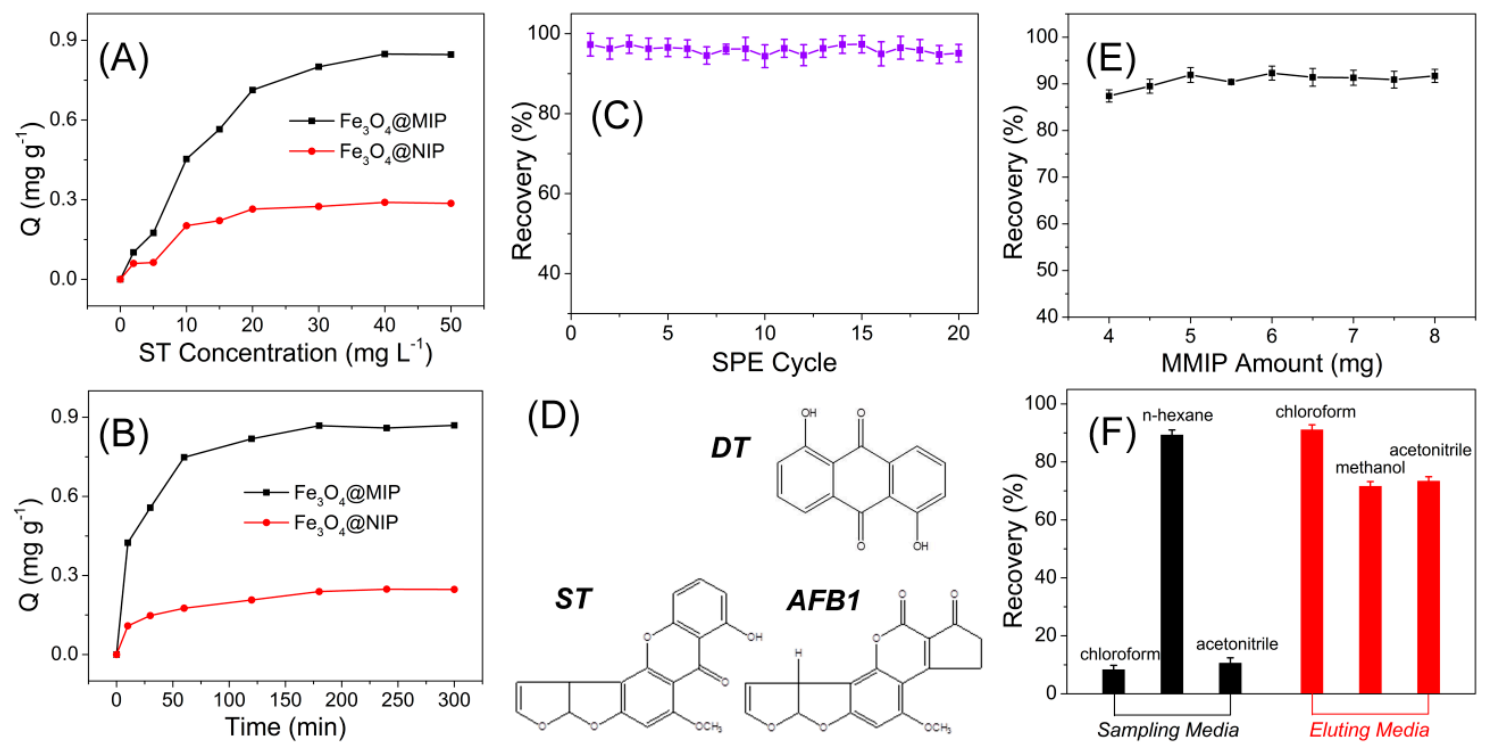

Figure 4. (A) Adsorption isotherms of $\mathrm{Fe}_{3} \mathrm{O}_{4} @ \mathrm{MIPs}$ and $\mathrm{Fe}_{3} \mathrm{O}_{4} @ \mathrm{NIPs}$ to ST; (B) kinetic uptake plot of $\mathrm{Fe}_{3} \mathrm{O}_{4} @$ MIPs and $\mathrm{Fe}_{3} \mathrm{O}_{4} @$ NIPs to ST; (C) evaluation of reusability of the mean squared prediction error (MSPE) column for ST analysis, with experimental conditions: $5 \mathrm{mg}$ of polymers, $3 \mathrm{~mL}$ of ST methanol solution $\left(20 \mathrm{mg} \cdot \mathrm{L}^{-1}\right.$ for kinetic uptake; 2 to $50 \mathrm{mg} \cdot \mathrm{L}^{-1}$ for adsorption isotherms), $25{ }^{\circ} \mathrm{C}$; (D) the structures of DT, ST and aflatoxin B1 (AFB1); (E) optimization of magnetic molecularly imprinted polymers (MMIP) amount for solid phase extraction (SPE); and (F) optimization of sampling media and eluting media for SPE.

Table 1. Evaluation of adsorption isotherm by the Langmuir and Freundlich models, and data for pseudo-first-order and pseudo-second-order rate constant, experimental $q_{e}$ values, intra-particle diffusion rate constant, and Elovich parameters.

\begin{tabular}{|c|c|c|c|c|c|}
\hline \multicolumn{3}{|c|}{ Freundlich Model } & \multicolumn{3}{|c|}{ Langmuir Model } \\
\hline$K_{F}$ & $n$ & $R^{2}$ & $Q_{m}$ & $R_{l}$ & $R^{2}$ \\
\hline 3.12 & 1.67 & 0.9486 & 0.92 & 0.85 & 0.9948 \\
\hline \multicolumn{3}{|c|}{ Pseudo-First-Order Kinetics } & \multicolumn{3}{|c|}{ Pseudo-Second-Order Kinetics } \\
\hline$K_{1}\left(\min ^{-1}\right)$ & $q_{e}(\mathrm{cal})\left(\mathrm{mg} \cdot \mathrm{g}^{-1}\right)$ & $R^{2}$ & $K_{2}\left(\min ^{-1}\right)$ & $q_{e}(\mathrm{cal})\left(\mathrm{mg} \cdot \mathrm{g}^{-1}\right)$ & $R^{2}$ \\
\hline 0.045 & 0.53 & 0.9726 & 0.019 & 0.91 & 0.9923 \\
\hline \multicolumn{3}{|c|}{ Intra-Particle Diffusion } & \multicolumn{3}{|c|}{ Elovich } \\
\hline$k_{\text {int }}\left(\mathrm{mg} \cdot \mathrm{g}^{-1} \cdot \mathrm{min}^{-1 / 2}\right)$ & $C\left(\mathrm{mg} \cdot \mathrm{g}^{-1}\right)$ & $R^{2}$ & $\alpha\left(\mathrm{mg} \cdot \mathrm{g}^{-1} \cdot \mathrm{min}^{-1}\right)$ & $\beta\left(\mathrm{g} \cdot \mathrm{mg}^{-1}\right)$ & $R^{2}$ \\
\hline 0.2987 & 1.3782 & 0.8832 & 0.98 & 0.88 & 0.9529 \\
\hline
\end{tabular}

To evaluate the specificity of the developed $\mathrm{Fe}_{3} \mathrm{O}_{4} @ \mathrm{MIPs}$ materials, the imprinting factors are introduced for comparison. The adsorption of the $\mathrm{Fe}_{3} \mathrm{O}_{4} @ \mathrm{MIPs}$ and $\mathrm{Fe}_{3} \mathrm{O}_{4} @ \mathrm{NIPs}$ to both ST and the structural analog, AFB1 (Figure 4D) were carried out at the same experimental conditions. The imprinting factor was defined as the ratio of $\mathrm{Q}_{\mathrm{MIPs}}$ to $\mathrm{Q}_{\mathrm{NIPs}}$, which represented adsorption 
capacity of MIP and NIP, respectively. As shown in Figure 5, the $\mathrm{Fe}_{3} \mathrm{O}_{4} @ \mathrm{MIPs}$ showed a significantly higher adsorption capacity of ST than AFB1, while the $\mathrm{Fe}_{3} \mathrm{O}_{4} @ \mathrm{NIPs}$ did not show such a difference, indicating that the template molecule had a relatively higher affinity for the imprinted polymer than its analog. Moreover, the imprinting factor of ST (2.8) was also much higher than its analog (1.4), further confirming the excellent recognition performance of $\mathrm{Fe}_{3} \mathrm{O}_{4} @ \mathrm{MIPs}$ to ST. Furthermore, co-existing experiments demonstrated similar results as above. Although ST and AFB1 have similar scaffold (xanthene), the differences in their spatial structures and functional groups caused a mismatch in the holes and binding sites, leading to the good selectivity to ST against AFB1. Due to utilizing DT as template for imprinting, the selectivity of DT is comparable to ST. However, in most cases, DT scarcely exist together with ST in grain samples; even during coexistence, the interference could be effectively reduced or totally eliminated via the extraction procedures [22]. Besides, owing to the well-constructed imprinting polymers, the $\mathrm{Fe}_{3} \mathrm{O}_{4} @ \mathrm{MIPs}$ showed insignificant response to the interferents, such as OTA, AFB2, AFM1, MC-LR, DON, and ZEN, compared with that of target ST.

The proposed fluorescent MIPs method gave a linear range of $0.05-5.0 \mathrm{mg} \cdot \mathrm{L}^{-1}$ with a detection limit ( $3 \mathrm{~s}$ ) of $9.1 \mu \mathrm{g} \cdot \mathrm{L}^{-1}$ for the detection of ST. The precision (relative standard deviation (RSD)) for eleven replicate detections of $0.5 \mathrm{mg} \cdot \mathrm{L}^{-1} \mathrm{ST}$ was $2.1 \%$. These results indicate that the $\mathrm{Fe}_{3} \mathrm{O}_{4} @ \mathrm{MIPs}$ can be used for the sensitive and selective SPE and determination of ST in complex samples. Compared with the previously-reported methods for ST determination in terms of sensitivity and linear range, the developed MIP method showed comparable performance (Table 2).
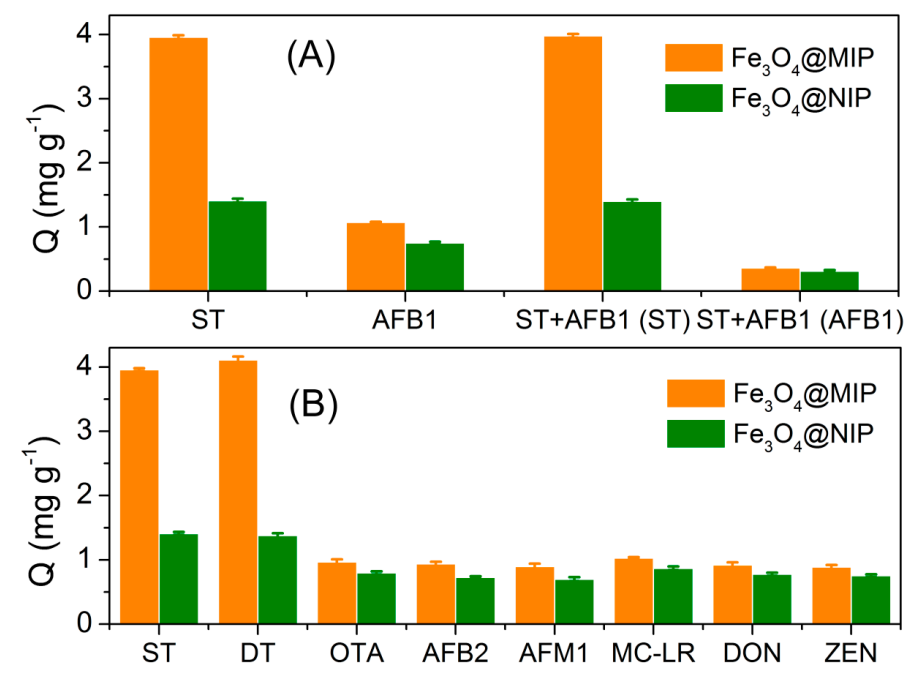

Figure 5. (A) Selective and competitive adsorptions of ST and AFB1 by $\mathrm{Fe}_{3} \mathrm{O}_{4} @ \mathrm{MIPs}$ and $\mathrm{Fe}_{3} \mathrm{O}_{4} @ \mathrm{NIPs}$; and (B) specificity of the developed MIP HPLC method for ST determination.

Table 2. Comparison of the developed magnetic MIP method with the previously-reported methods for ST determination.

\begin{tabular}{cccc}
\hline Method & Detection Limit $\left(\mu \mathrm{g} \cdot \mathbf{L}^{-\mathbf{1}}\right)$ & Linear Range $\left(\boldsymbol{\mu g} \cdot \mathbf{L}^{-\mathbf{1}}\right)$ & Reference \\
\hline ELISA & 0.36 & NA & {$[6]$} \\
GC-MS & 3 & $10-150$ & {$[3]$} \\
LC-MS & 3 & NA & {$[5]$} \\
LC-MS & 3 & NA & {$[7]$} \\
HPLC & 9 & $50-5000$ & This Work \\
Fluorescence & 19 & $50-2000$ & {$[22]$} \\
Fluorescence & 13 & $20-1000$ & {$[24]$} \\
\hline
\end{tabular}

GC-MS: gas chromatography-mass spectrometry; LC-MS: liquid chromatography-mass spectrometry; HPLC: high-performance liquid chromatography; NA: Not applicable. 


\subsection{Real Sample Analysis}

To demonstrate the applicability of the developed magnetic MIP-HPLC method for real sample analysis, it was applied for the selective isolation and enrichment of ST in food samples via spiked recovery experiments. As can be seen in the chromatograms of the cereal samples before and after being spiked with ST at $50 \mu \mathrm{g} \cdot \mathrm{kg}^{-1}$, ST appeared at $7.86 \mathrm{~min}$ after being spiked, and other irrelevant compounds in the sample showed insignificant interference to the measurement (Figure 6). As shown in Table 3, the obtained recoveries of the spiked samples were in the range of $85.2-88.1 \%$ for wheat, $80.6-88.7 \%$ for rice, and $82.9-88.6 \%$ for millet, with relative standard deviation (RSD) less than $5.6 \%$.
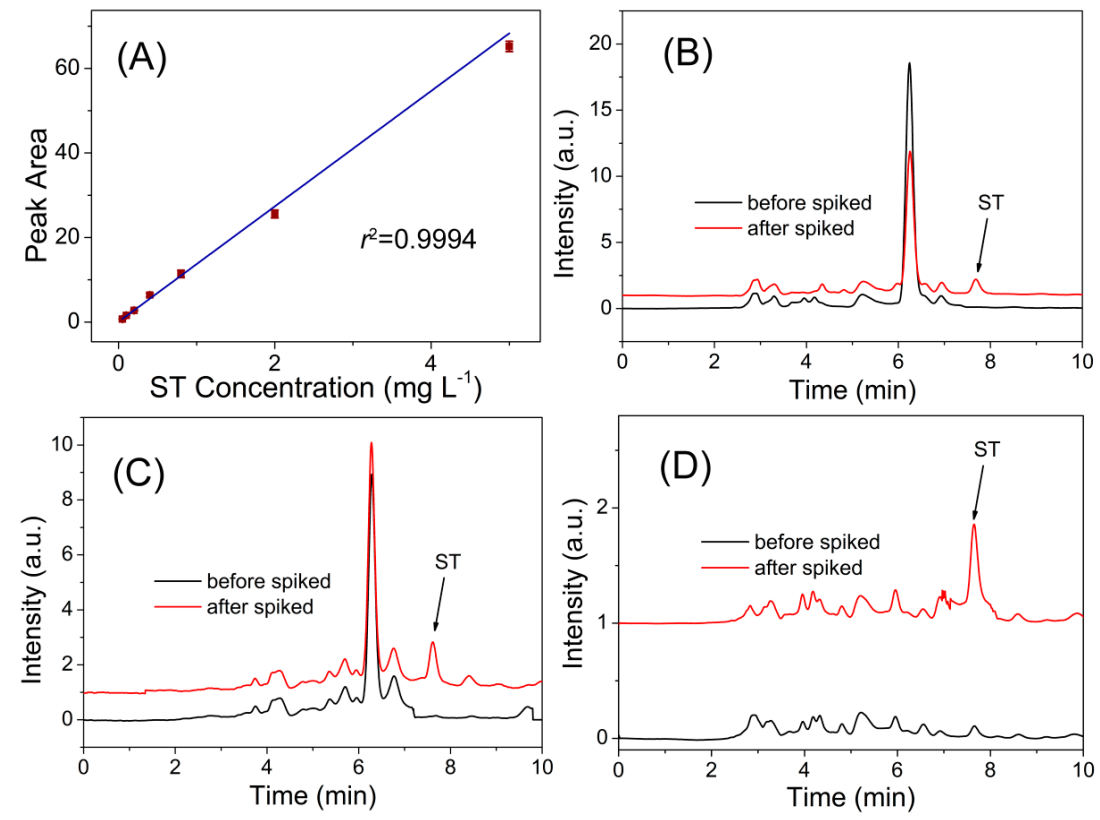

Figure 6. (A) The linear response of the developed MIP-HPLC method to ST. (B-D) Chromatograms of blank sample (black line) and spiked with $50.0 \mathrm{ug} \cdot \mathrm{kg}^{-1} \mathrm{ST}$ (red line) for analyses of: wheat (B); rice (C); and millet (D).

Table 3. Application of the developed MIP-HPLC method for the determination of ST in real samples.

\begin{tabular}{ccccc}
\hline Samples & $\begin{array}{c}\text { Spiked Amount } \\
\left(\boldsymbol{\mu g} \cdot \mathbf{k g}^{-\mathbf{1}} \mathbf{)}\right.\end{array}$ & $\begin{array}{c}\text { Determined Amount } \\
\left(\boldsymbol{\mu g} \cdot \mathbf{k g}^{-\mathbf{1}}, \mathbf{M e a n} \pm \mathbf{S D}\right)\end{array}$ & Recovery (\%) & RSD (\%) \\
\hline \multirow{3}{*}{ Wheat } & 50 & $44.1 \pm 0.9$ & $88.1 \pm 1.7$ & 1.1 \\
& 100 & $85.2 \pm 4.8$ & $85.2 \pm 4.8$ & 5.6 \\
\hline \multirow{3}{*}{ Rice } & 200 & $174.4 \pm 0.7$ & $87.2 \pm 0.4$ & 0.4 \\
& 50 & $43.6 \pm 1.9$ & $87.2 \pm 3.7$ & 4.4 \\
& 100 & $88.7 \pm 1.1$ & $88.7 \pm 1.1$ & 1.2 \\
Millet & 200 & $161.2 \pm 1.4$ & $80.6 \pm 0.7$ & 0.9 \\
& 50 & $41.5 \pm 1.7$ & $82.9 \pm 3.5$ & 4.1 \\
& 100 & $88.6 \pm 1.4$ & $88.6 \pm 1.4$ & 1.6 \\
\hline
\end{tabular}

SD: standard deviation; RSD: relative standard deviation.

\section{Conclusions}

In this study, MIPs were synthesized onto $\mathrm{Fe}_{3} \mathrm{O}_{4} @ \mathrm{SiO}_{2}$ magnetic particles with a uniform core-shell structure by surface imprinting and nanotechnology. The $\mathrm{Fe}_{3} \mathrm{O}_{4} @ \mathrm{MIPs}$ showed remarkable specificity target ST along with sensitive response. The successful selective separation and enrichment 
of ST in food samples indicated that the $\mathrm{Fe}_{3} \mathrm{O}_{4} @ M I P s$ was ideal solid-phase extraction material and had the potential of applying to detect the illegal addition of ST in food.

Acknowledgments: This work was supported by Beijing Municipal Science and Technology Project (No. Z171100004517013), State Key Program of National Natural Science Foundation of China (No. 31430068), and National Key Research and Development Program of China (No. 2016YFD0401202).

Author Contributions: Jing-Min Liu and Shuo Wang conceived and designed the experiments; Shu-Yuan Wei and Jing-Min Liu performed the experiments; Jing-Min Liu and Guo-Zhen Fang analyzed the data; Jing-Min Liu and Hui-Lin Liu contributed reagents/materials/analysis tools; and Jing-Min Liu wrote the paper.

Conflicts of Interest: The authors declare no conflict of interest.

\section{References}

1. Zheng, R.; Xu, H.; Wang, W.; Zhan, R.; Chen, W. Simultaneous determination of aflatoxin B-1, B-2, G(1), G(2), ochratoxin A, and sterigmatocystin in traditional Chinese medicines by LC-MS-MS. Anal. Bioanal. Chem. 2014, 406, 3031-3039. [CrossRef] [PubMed]

2. Wegner, S.; Bauer, J.I.; Dietrich, R.; Maertlbauer, E.; Usleber, E.; Gottschalk, C.; Gross, M. A highly specific competitive direct enzyme immunoassay for sterigmatocystin as a tool for rapid immunochemotaxonomic differentiation of mycotoxigenic Aspergillus species. Lett. Appl. Microbiol. 2017, 64, 124-130. [CrossRef] [PubMed]

3. Hossain, M.Z.; Goto, T. Determination of sterigmatocystin in grain using gas chromatography-mass spectrometry with an on-column injector. Mycotoxin Res. 2015, 31, 17-22. [CrossRef] [PubMed]

4. Nemeth, Z.; Molnar, A.P.; Fejes, B.; Novak, L.; Karaffa, L.; Keller, N.P.; Fekete, E. Growth-phase sterigmatocystin formation on lactose is mediated via low specific growth rates in Aspergillus nidulans. Toxins 2016, 8, 354. [CrossRef] [PubMed]

5. Ok, H.E.; Tian, F.; Hong, E.Y.; Paek, O.; Kim, S.-H.; Kim, D.; Chun, H.S. Harmonized collaborative validation of aflatoxins and sterigmatocystin in white rice and sorghum by liquid chromatography coupled to tandem mass spectrometry. Toxins 2016, 8, 371. [CrossRef] [PubMed]

6. Li, M.; Li, P.; Wu, H.; Zhang, Q.; Ma, F.; Zhang, Z.; Ding, X.; Wang, H. An ultra-sensitive monoclonal antibody-based competitive enzyme immunoassay for sterigmatocystin in cereal and oil products. PLOS ONE 2014, 9, e106415. [CrossRef] [PubMed]

7. Luan, L.; Chen, N.; Han, Z.; Liu, X.; Zheng, Y.; Wu, Y. Simultaneous determination of aflatoxin B-1, aflatoxin B-2, mycophenolic acid and sterigmatocystin in grape pomace by UHPLC-MS/MS. World Mycotoxin J. 2014, 7, 121-129. [CrossRef]

8. Sharma, P.S.; D'Souza, F.; Kutner, W. Molecular imprinting for selective chemical sensing of hazardous compounds and drugs of abuse. TrAC Trends Anal. Chem. 2012, 34, 59-77. [CrossRef]

9. Diaz-Diaz, G.; Antuna-Jimenez, D.; Carmen Blanco-Lopez, M.; Jesus Lobo-Castanon, M.; Miranda-Ordieres, A.J.; Tunon-Blanco, P. New materials for analytical biomimetic assays based on affinity and catalytic receptors prepared by molecular imprinting. TrAC Trends Anal. Chem. 2012, 33, 68-80. [CrossRef]

10. Chen, L.; $\mathrm{Xu}, \mathrm{S}$; $\mathrm{Li}, \mathrm{J}$. Recent advances in molecular imprinting technology: Current status, challenges and highlighted applications. Chem. Soc. Rev. 2011, 40, 2922-2942. [CrossRef] [PubMed]

11. Huang, L.; Li, M.; Wu, D.; Ma, X.; Wu, Z.; Xiang, S.; Chen, S. Molecularly imprinted nanofiber film for sensitive sensing 2,4,6-tribromophenol. Polymers 2016, 8, 222. [CrossRef]

12. Asman, S.; Mohamad, S.; Sarih, N.M. Effects of RAFT agent on the selective approach of molecularly imprinted polymers. Polymers 2015, 7, 484-503. [CrossRef]

13. Yusof, N.A.; Ab Rahman, S.K.; Hussein, M.Z.; Ibrahim, N.A. Preparation and characterization of molecularly imprinted polymer as SPE sorbent for melamine isolation. Polymers 2013, 5, 1215-1228. [CrossRef]

14. Wang, X.Y.; Yu, J.L.; Kang, Q.; Shen, D.Z.; Li, J.H.; Chen, L.X. Molecular imprinting ratiometric fluorescence sensor for highly selective and sensitive detection of phycocyanin. Biosens. Bioelectron. 2016, 77, 624-630. [CrossRef] [PubMed]

15. Uzun, L.; Turner, A.P.F. Molecularly-imprinted polymer sensors: Realising their potential. Biosens. Bioelectron. 2016, 76, 131-144. [CrossRef] [PubMed] 
16. Panagiotopoulou, M.; Salinas, Y.; Beyazit, S.; Kunath, S.; Duma, L.; Prost, E.; Mayes, A.G.; Resmini, M.; Bui, B.T.S.; Haupt, K. Molecularly imprinted polymer coated quantum dots for multiplexed cell targeting and imaging. Angew. Chem. Int. Ed. 2016, 55, 8244-8248. [CrossRef] [PubMed]

17. Baggiani, C.; Anfossi, L.; Giovannoli, C. Solid phase extraction of food contaminants using molecular imprinted polymers. Anal. Chim. Acta 2007, 591, 29-39. [CrossRef] [PubMed]

18. Kandimalla, V.B.; Ju, H.X. Molecular imprinting: A dynamic technique for diverse applications in analytical chemistry. Anal. Bioanal. Chem. 2004, 380, 587-605. [CrossRef] [PubMed]

19. Yin, Y.; Yan, L.; Zhang, Z.; Wang, J.; Lv, P. Magnetic molecularly imprinted polymer preconcentration of 4-chlorophenol with determination by high-performance liquid chromatography. Anal. Lett. 2017, 50, 117-134. [CrossRef]

20. Fang, G.Z.; Fan, C.; Liu, H.L.; Pan, M.F.; Zhu, H.D.; Wang, S. A novel molecularly imprinted polymer on CdSe/ZnS quantum dots for highly selective optosensing of mycotoxin zearalenone in cereal samples. RSC Adv. 2014, 4, 2764-2771. [CrossRef]

21. Liu, H.L.; Fang, G.Z.; Zhu, H.D.; Wang, S. Application of molecularly imprinted polymer appended onto $\mathrm{CdSe} / \mathrm{ZnS}$ quantum dots for optosensing of tocopherol in rice. Food Anal. Methods 2014, 7, 1443-1450. [CrossRef]

22. Xu, L.H.; Fang, G.Z.; Pan, M.F.; Wang, X.F.; Wang, S. One-pot synthesis of carbon dots-embedded molecularly imprinted polymer for specific recognition of sterigmatocystin in grains. Biosens. Bioelectron. 2016, 77, 950-956. [CrossRef] [PubMed]

23. Qian, K.; Fang, G.Z.; Wang, S. Highly sensitive and selective novel core-shell molecularly imprinted polymer based on $\mathrm{NaYF}_{4}: \mathrm{Yb}^{3+}, \mathrm{Er}^{3+}$ upconversion fluorescent nanorods. RSC Adv. 2013, 3, 3825-3828. [CrossRef]

24. Liu, J.-M.; Cao, F.-Z.; Fang, G.-Z.; Wang, S. Upconversion nanophosphor-involved molecularly imprinted fluorescent polymers for sensitive and specific recognition of sterigmatocystin. Polymers 2017, 9, 299. [CrossRef]

25. Machynakova, A.; Hrobonova, K. Preparation and application of magnetic molecularly imprinted polymers for the selective extraction of coumarins from food and plant samples. Anal. Methods 2017, 9, 2168-2176. [CrossRef]

26. Shi, S.; Fan, D.; Xiang, H.; Li, H. Effective synthesis of magnetic porous molecularly imprinted polymers for efficient and selective extraction of cinnamic acid from apple juices. Food Chem. 2017, 237, 198-204. [CrossRef] [PubMed]

27. Liu, M.; Li, X.; Li, J.; Wu, Z.; Wang, F.; Liu, L.; Tan, X.; Lei, F. Selective separation and determination of glucocorticoids in cosmetics using dual-template magnetic molecularly imprinted polymers and HPLC. J. Colloid Interface Sci. 2017, 504, 124-133. [CrossRef] [PubMed]

28. Ansari, S. Application of magnetic molecularly imprinted polymer as a versatile and highly selective tool in food and environmental analysis: Recent developments and trends. TrAC Trends Anal. Chem. 2017, 90, 89-106. [CrossRef]

29. Ji, W.; Sun, R.; Duan, W.; Wang, X.; Wang, T.; Mu, Y.; Guo, L. Selective solid phase extraction of chloroacetamide herbicides from environmental water samples by amphiphilic magnetic molecularly imprinted polymers. Talanta 2017, 170, 111-118. [CrossRef] [PubMed]

30. Wang, X.; Huang, P.; Ma, X.; Wang, H.; Lu, X.; Du, X. Preparation and evaluation of magnetic core-shell mesoporous molecularly imprinted polymers for selective adsorption of tetrabromobisphenol S. Talanta 2017, 166, 300-305. [CrossRef] [PubMed]

31. Liu, J.-M.; Yan, X.-P. Ultrasensitive, selective and simultaneous detection of cytochrome c and insulin based on immunoassay and aptamer-based bioassay in combination with Au/Ag nanoparticle tagging and ICP-MS detection. J. Anal. At. Spectrom. 2011, 26, 1191-1197. [CrossRef]

32. Liu, Y.X.; Liu, L.; He, Y.H.; He, Q.H.; Ma, H. Quantum-dots-encoded-microbeads based molecularly imprinted polymer. Biosens. Bioelectron. 2016, 77, 886-893. [CrossRef] [PubMed]

(C) 2017 by the authors. Licensee MDPI, Basel, Switzerland. This article is an open access article distributed under the terms and conditions of the Creative Commons Attribution (CC BY) license (http://creativecommons.org/licenses/by/4.0/). 